\title{
A PRÁTICA DE EXERCÍCIOS FÍSICOS E O EQUILÍBRIO DE IDOSOS ATIVOS
}

Adriane Ribeiro Teixeira; Universidade Federal do Rio Grande do Sul e Universidade Federal de São Paulo; adriane.teixeira@gmail.com

Sabrina Nuñes Gonçalves; Universidade Federal do Rio Grande do Sul; Sabrina.goncalves@ufrgs.br Maira Rozenfeld Olchik - Universidade Federal do Rio Grande do Sul; mairarozenfeld@hotmail.com

\section{RESUMO}

Introdução: $\mathrm{O}$ equilíbrio é uma capacidade complexa, dependente da integração de diversos sistemas. A prática de exercícios físicos contribui para a manutenção do controle postural. Objetivo: Avaliar a influência do tempo de prática de exercícios físicos no equilíbrio de idosos. Métodos: Estudo transversal realizado com idosos participantes de atividades em centro comunitário. $\mathrm{O}$ equilíbrio foi avaliado pelo Teste Alcance Funcional (AF) que determina a distância que o idoso é capaz de alcançar, sem se movimentar e mantendo o equilíbrio. São realizadas três medições e é calculada a média delas. Se esta média é $>25,4 \mathrm{~cm}$ há baixa probabilidade de queda (equilíbrio adequado), valores $\leq 25,4 \mathrm{~cm}$ indicam maior chance de quedas. A prática e tempo de exercícios físicos (TEF) foi coletada em entrevista. Para análise dos resultados, foram criados dois grupos, G1 com idosos com TEF $\leq 5$ anos e G2 de idosos com TEF $>5$ anos. A comparação entre os grupos foi realizada com o teste Qui-quadrado de Pearson. Resultados: Compuseram a amostra 53 idosos, sendo 46 (86,8\%) do sexo feminino. A idade variou entre 60 e 82 anos (média 68,7士10,8). No G1 32 $(74,4 \%)$ apresentaram $\mathrm{AF}>25,4 \mathrm{~cm}$ e $11(25,6 \%) \mathrm{AF} \leq 25,4 \mathrm{~cm}$, enquanto no $\mathrm{G} 29$ (90\%) apresentaram $\mathrm{AF}>25,4 \mathrm{~cm}$ e $1(10 \%) \mathrm{AF} \leq 25,4 \mathrm{~cm}$. Esta diferença entre os grupos não foi estatisticamente significativa $(p=0,289)$. Conclusão: $\mathrm{Na}$ amostra estudada não houve influência do tempo de prática de exercícios físicos e o equilíbrio dos grupos medido pelo teste do AF.

Palavras-chave: Idoso; Equiíbrio Postural; Exercício Físico. 